Pacific Journal of Mathematics

PARTIAL REGULARITY OF SOLUTIONS TO THE 


\title{
PARTIAL REGULARITY OF SOLUTIONS TO THE NAVIER-STOKES EQUATIONS
}

\author{
VLADIMIR SCHEFFER
}

At the first instant of time when a viscous incompressible fluid flow with finite kinetic energy in three space becomes singular, the singularities in space are concentrated on a closed set whose one dimensional Hausdorff measure is finite.

\$1. Introduction. Let $v: R^{3} \times R^{+} \rightarrow R^{3}$ (where $R^{+}=$ $\{t \in R: t>0\}$ represents time) be a weak solution to the Navier-Stokes equations of incompressible viscous fluid flow in 3 dimensional euclidean space with finite initial kinetic energy and viscosity equal to 1 . Our definition of weak solution coincides with Leray's definition of "solution turbulente" [4, pp. 240, 241, 235]. In that paper, Leray showed that weak solutions always exist for prescribed initial conditions with finite energy. He also proved the following regularity theorem:

LERAY'S THEOREM. There exists a finite or countable sequence $J_{0}, J_{1}$, $J_{2}, \cdots$ such that $J_{q} \subset R^{+}, J_{0}=\{t: t>a\}$ for some $a, J_{q}$ is an open interval for $q>0$, the $J_{q}$ are disjointed, the Lebesgue measure of $R^{+}-\cup_{q \geqq 0} J_{q}$ is zero, $v$ can be modified on a set of Lebesgue measure zero so that its restriction to each $R^{3} \times J_{q}$ becomes smooth, and

$$
\sum_{q>0}\left(\text { length }\left(J_{q}\right)\right)^{1 / 2}
$$

is finite.

It is not known whether there exist $v$ with singularities $\left(J_{0}=R^{+}\right.$is a possibility). The purpose of this paper is to prove the following theorem on the nature of possible singularities of $v$. We assume that $v$ has been modified to be smooth on each $R^{3} \times J_{q}$.

THEOREM 1. Let $t_{0}$ be the right endpoint of an interval $J_{q}$ with $q>0$. Then there exists a closed set $S \subset R^{3}$ such that $v$ can be extended to a continuous function on

$$
\left(R^{3} \times J_{q}\right) \cup\left(\left(R^{3}-S\right) \times\left\{t_{0}\right\}\right)
$$

and the 1 dimensional Hausdorff measure of $S$ is finite. 
The definition of Hausdorff measure can be found in [2, p. 171]. We note in passing that Leray's theorem yields

THEOREM 2. The $1 / 2$ dimensional Hausdorff measure of $R^{+}-\cup_{q \geqq 0}$ $J_{q}$ is zero.

There is a proof of Theorem 2 in [7]. Research on the Hausdorff dimension of singularities of fluid flow was started by Mandelbrot [5]. The conclusion of Theorem 1 resembles the partial regularity results in [1, IV. $13(6)$, p. 126].

Leray's theorem has been generalized by M. Shinbrot and S. Kaniel to flows on a bounded domain [8]. I do not know whether Theorem 1 generalizes to that case.

Notation. We set $(a, b)=\{t: a<t<b\},[a, b)=\{t: a \leqq t<b\}$, and so on for $(a, b]$ and $[a, b]$. If $f$ is a function defined on a subset of $R^{3} \times R$ then $f_{i,}, f_{, i j}$, etc. are the partial derivatives $\left(\partial / \partial x_{i}\right) f,\left(\partial^{2} / \partial x_{i} \partial x_{j}\right) f$, etc. where $x_{1}, x_{2}, x_{3}$ are the coordinates of $R^{3}$. The partial derivative with respect to the $R$ variable is denoted by $f_{, t}$. We set $D^{0} f=f$, $D^{1} f=D f=\left(f_{, 1}, f_{, 2}, f_{3,3}\right), D^{2} f=\left(f_{i j}\right)$ for $i, j \in\{1,2,3\}$, and so forth for $D^{n} f$. We let $\left|D^{n} f(x, t)\right|$ be the euclidean norm. If, in addition, $f$ has range $R^{3}$ then $f_{l}$ is the corresponding component of $f$ for $i=1,2,3$. In that case we set $\operatorname{div}(f)=\sum_{i=1}^{3} f_{i, l}$. The summation convention for repeated indices is used throughout, e.g. $\operatorname{div}(f)=f_{i, i}$. If $f$ is a function defined on a subset of $R^{3}$ then $D f(x)$ and $|D f(x)|$ are the gradient and its norm.

An absolute constant is a finite positive constant that does not depend on any of the parameters in this paper. The symbol $C$ will always denote an absolute constant, and the value of $C$ may change from one line to the next (e.g. $2 C \leqq C$ ). The symbols $C_{1}, C_{2}, C_{3}, \cdots$ are not treated in this way, and their value does not change in the course of the paper.

We begin to prove Theorem 1. Let $\phi: R^{3} \times\{t: t<0\} \rightarrow R^{+}$be defined by

$$
\phi(x, t)=(2 \sqrt{\pi})^{-3}(-t)^{-3 / 2} \exp \left(|x|^{2} /(4 t)\right) .
$$

Since $\phi$ is just the fundamental solution to the heat equation running backwards in time, it satisfies

$$
\phi_{, i i}=-\phi_{, t}
$$

and

$$
\lim _{\epsilon \downarrow 0} \int_{R^{3}} f(y, t-\epsilon) \phi(y-x,-\epsilon) d y=f(x, t)
$$


if $f$ is continuous at $(x, t)$ and $\int_{R^{3}}|f(y, s)|^{2} d y$ is bounded as a function of

s. We also define $\psi: R^{3} \times\{t: t<0\} \rightarrow R^{+}$by

$$
\psi(x, t)=-(4 \pi)^{-1} \int_{R^{3}} \phi(y, t)|y-x|^{-1} d y .
$$

This Newtonian potential of $\phi$ satisfies the Poisson equation

$$
\psi_{, i i}=\phi
$$

We have the estimates

$$
\begin{aligned}
& \left|D^{n} \phi(x, t)\right| \leqq E_{n}\left(|x|^{2}-t\right)^{-(n+3) / 2}, \\
& \left|D^{n} \psi(x, t)\right| \leqq E_{n}\left(|x|^{2}-t\right)^{-(n+1) / 2}
\end{aligned}
$$

where $E_{n}$ is an absolute constant for each $n$.

Two consequences of the definition of weak solution are:

$$
\int_{R^{3}}|v(x, t)|^{2} d x \leqq C_{1} \quad \text { if } \quad t \in \bigcup_{q \geqq 0} J_{q}
$$

$$
\int_{R^{3} \times R^{+}}|D v|^{2} \leqq C_{1}
$$

for some $C_{1}<\infty$, and

$$
\operatorname{div}(v)(x, t)=0 \quad \text { if } \quad t \in \bigcup_{q \geq 0} J_{q} .
$$

A third consequence is the following lemma:

LEMMA 1.1. If $\left[t_{1}, t_{2}\right] \subset J_{q}$ then for $i \in\{1,2,3\}$ and $x \in R^{3}$ we have

$$
\begin{aligned}
& v_{i}\left(x, t_{2}\right) \\
& =\int_{R^{3}} v_{i}\left(y, t_{1}\right) \phi\left(y-x, t_{1}-t_{2}\right) d y \\
& \quad+\int_{t_{1}}^{t_{2}} \int_{R^{3}} v_{J}(y, t) v_{i}(y, t) \phi_{, j}\left(y-x, t-t_{2}\right) d y d t \\
& \quad-\int_{t_{1}}^{t_{2}} \int_{R^{3}} v_{j}(y, t) v_{k}(y, t) \psi_{, i j k}\left(y-x, t-t_{2}\right) d y d t .
\end{aligned}
$$


Proof. We fix $i \in\{1,2,3\}$ and $x \in R^{3}$. Let $f: R^{3} \times\left\{t: t<t_{2}\right\} \rightarrow R^{3}$ be given by

$$
\begin{aligned}
& f_{l}(y, t)=\phi\left(y-x, t-t_{2}\right)-\psi_{, i j}\left(y-x, t-t_{2}\right) \text { if } j=i, \\
& f_{j}(y, t)=-\psi_{, i j}\left(y-x, t-t_{2}\right) \text { if } j \neq i .
\end{aligned}
$$

We were careful not to write $\psi_{, i i}$ in the first identity of (1.9) because there is no summation over the index $i$. Using (1.4) we obtain

$$
\begin{aligned}
\operatorname{div}(f)(y, t) & =\phi_{, i}\left(y-x, t-t_{2}\right)-\psi_{, i j j}\left(y-x, t-t_{2}\right) \\
& =\phi_{, i}\left(y-x, t-t_{2}\right)-\phi_{, i}\left(y-x, t-t_{2}\right)=0 .
\end{aligned}
$$

Now take $0<\epsilon<t_{2}-t_{1}$. The definition of weak solution, (1.10), and the good behavior of $f$ on $R^{3} \times\left[t_{1}, t_{2}-\epsilon\right]$ allow us to write (see (1.6))

$$
\begin{gathered}
\int_{R^{3}} v_{j}\left(y, t_{2}-\epsilon\right) f_{j}\left(y, t_{2}-\epsilon\right) d y \\
-\int_{R^{3}} v_{j}\left(y, t_{1}\right) f_{j}\left(y, t_{1}\right) d y \\
=\int_{R^{3} \times\left[t_{1}, t_{2}-\epsilon\right]}\left(v_{j}\right)\left(f_{j, k k}+f_{j, t}\right) \\
-\int_{R^{3} \times\left[t_{1}, t_{2}-\epsilon\right]} v_{k} v_{j, k} f_{j .}
\end{gathered}
$$

Integration by parts with respect to the $x_{j}$ and $x_{k}$ variables, (1.6), and (1.7) yield

$$
\begin{gathered}
\int_{R^{3}} v_{j}\left(y, t_{2}-\epsilon\right) \psi_{, i j}(y-x,-\epsilon) d y=0, \\
\int_{R^{3}} v_{j}\left(y, t_{1}\right) \psi_{, i j}\left(y-x, t_{1}-t_{2}\right) d y=0 \\
\int_{t_{1}}^{t_{2}-\epsilon} \int_{R^{3}} v_{j}(y, t)\left(\psi_{, j i k k}\left(y-x, t-t_{2}\right)\right. \\
\left.\quad+\psi_{, i j t}\left(y-x, t-t_{2}\right)\right) d y d t=0, \\
\int_{R^{3} \times\left[t_{1}, t_{2}-\epsilon\right]} v_{k} v_{j, k} f_{j} \\
=-\int_{R^{3} \times\left[t_{1}, t_{2}-\epsilon\right]} v_{k} v_{j j} f_{j, k} .
\end{gathered}
$$


Identities (1.9), (1.11), (1.12), (1.2) yield

$$
\begin{aligned}
\int_{R^{3}} & v_{i}\left(y, t_{2}-\epsilon\right) \phi(y-x,-\epsilon) d y \\
& -\int_{R^{3}} v_{i}\left(y, t_{1}\right) \phi\left(y-x, t_{1}-t_{2}\right) d y \\
= & \int_{t_{1}}^{t_{2}-\epsilon} \int_{R^{3}} v_{i}(y, t)\left(\phi_{, k k}\left(y-x, t-t_{2}\right)\right. \\
& \left.+\phi_{, t}\left(y-x, t-t_{2}\right)\right) d y d t \\
& +\int_{R^{3} \times\left[t_{1}, t_{2}-\epsilon\right]} v_{k} v_{j} f_{j, k} \\
= & +\int_{t_{1}}^{t_{2}-\epsilon} \int_{R^{3}} v_{k}(y, t) v_{i}(y, t) \phi_{, k}\left(y-x, t-t_{2}\right) d y d t \\
& -\int_{t_{1}}^{t_{2}-\epsilon} \int_{R^{3}} v_{k}(y, t) v_{j}(y, t) \psi_{, i j k}\left(y-x, t-t_{2}\right) d y d t .
\end{aligned}
$$

Now (1.13), (1.6), and (1.2) yield the conclusion of the lemma.

For $a \in R^{3}$ and $0<r<\infty$ we set

$$
B(a, r)=\left\{x \in R^{3}:|x-a| \leqq r\right\} .
$$

If $X$ is a set and $f: X \rightarrow R$ is a function we write

$$
\sup (f, X)=\operatorname{supremum}\{f(x): x \in X\} .
$$

LEMMA 1.2. Let $f: B(a, r) \rightarrow R$ be a smooth function and let $B(b, r / 4) \subset B(a, r)$. Then

$$
\int_{B(a, r)}|f|^{2} \leqq C r^{2}\left(\int_{B(a, r)}|D f|^{2}\right)+C r^{3} \sup \left(|f|^{2}, B(b, r / 4)\right) .
$$

Proof. Let $\mathscr{L}$ be the set of lines $L$ passing through $b$. Let $\mu$ be the rotation invariant Radon measure on $\mathscr{L}$ that satisfies $\mu(\mathscr{L})=1$. For each $L \in \mathscr{L}$ the fundamental theorem of calculus yields

$$
\begin{aligned}
& \int_{B(a, r) \cap L}|f|^{2} \\
& \leqq C r^{2}\left(\int_{(B(a, r)-B(b, r / 4)) \cap L}|D f|^{2}\right) \\
& \quad+C \sup \left(|f|^{2}, B(b, r / 4) \cap L\right) r .
\end{aligned}
$$


Hence

$$
\begin{aligned}
\int_{B(a, r)}|f|^{2} \leqq & C r^{2} \int_{\mathscr{L}}\left(\int_{B(a, r) \cap L}|f|^{2}\right) d \mu \\
\leqq & C r^{4} \int_{\mathscr{L}}\left(\int_{(B(a, r)-B(b, r / 4)) \cap L}|D f|^{2}\right) d \mu \\
& +C r^{3} \sup \left(|f|^{2}, B(b, r / 4)\right) \\
\leqq & C r^{2}\left(\int_{B(a, r)-B(b, r / 4)}|D f|^{2}\right) \\
& +C r^{3} \sup \left(|f|^{2}, B(b, r / 4)\right) .
\end{aligned}
$$

2. The basic estimate. Throughout this section we fix $0<$ $d_{0}<\left(\text { length }\left(J_{q}\right)\right)^{1 / 2}$, where $J_{q}$ is the interval in the hypotheses of Theorem 1 , and we fix $x_{0} \in R^{3}$. We define $u: R^{3} \times[-1,0) \rightarrow R^{3}$ by

$$
u(x, t)=d_{0} v\left(x_{0}+d_{0} x, t_{0}+d_{0}^{2} t\right)
$$

where $t_{0}$ is the right endpoint of $J_{q}$ as in Theorem 1 , and observe that $u$ satisfies the Navier-Stokes equations with viscosity 1 in the same way as $v$. Therefore Lemma 1.1 allows us to use the identity

$$
\begin{aligned}
u_{i}(x, t)= & \int_{R^{3}} u_{i}(y,-1) \phi^{\prime}(y,-1) d y \\
& +\left(\int_{R^{3} \times[-1, t\}} u_{j} u_{i} \phi_{, J}^{\prime}\right) \\
& -\int_{R^{3} \times[-1, t]} u_{j} u_{k} \psi_{, i j k}^{\prime}
\end{aligned}
$$

for $-1<t<0$, where

$$
\phi^{\prime}(y, s)=\phi(y-x, s-t), \psi^{\prime}(y, s)=\psi(y-x, s-t) .
$$

We also set

$$
\begin{aligned}
A_{p} & =\left\{(y, s) \in R^{3} \times R:|y| \leqq 1-2^{-p}, 2^{-2 p}-1 \leqq s<0\right\} \\
B_{p} & =\left\{(y, s) \in R^{3} \times R: 1-2^{1-p} \leqq|y| \leqq 1+2^{1-p},-1 \leqq s \leqq 0\right\} \\
C_{t} & =\left\{(y, s) \in R^{3} \times R:-1 \leqq s \leqq t\right\} \\
D & =\left\{(y, s) \in R^{3} \times R:|y| \geqq 3 / 2,-1 \leqq s \leqq 0\right\} \\
E & =\left\{y \in R^{3}:|y| \geqq 3 / 2\right\} \\
F & =\left\{y \in R^{3}:|y| \leqq 2\right\}
\end{aligned}
$$


for $p=1,2,3, \cdots$ and $-1<t<0$. In addition we set

$$
A_{0}=\varnothing, \quad B_{-2}=B_{-1}=B_{0}=B_{1}
$$

LEMMA 2.1. There exist absolute constants $C_{2}, C_{3}$ such that

$$
\begin{aligned}
|u(x, t)| \leqq & C_{3}(t+1)^{-1 / 2} \int_{R^{3}}|u(y,-1)|^{2}(1+|y|)^{-4} d y \\
& +C_{3}(t+1)^{-3 / 2} \int_{C_{1}}|u(y, s)|^{2}(1+|y|)^{-4} d y d s \\
& +C_{3}(t+1)^{-1 / 2} \int_{F}|D u(y,-1)|^{2} d y \\
& +C_{3}(t+1)^{-3 / 2}\left(\int_{B_{1} \cap C_{t}}|D u|^{2}\right) \\
& +C_{3}\left(\sum_{p=1}^{n+1} 2^{2 p} \int_{B_{p}}|D u|^{2}\right) \\
& +C_{2}\left(\sum_{p=1}^{n+3} 2^{-p} \sup \left(|u|^{2}, A_{p} \cap C_{t}\right)\right)+C_{2}^{-1} 2^{-12}
\end{aligned}
$$

holds if $(x, t) \in A_{n+1}-A_{n}$ for $n \geqq 0$.

Proof. We fix $(x, t) \in A_{n+1}-A_{n}$ and define $\phi^{\prime}, \psi^{\prime}$ as in (2.3). We set

$$
G_{p}=\left\{(y, s) \in R^{3} \times R:|y-x| \leqq 2^{1-p}, t-2^{-2 p} \leqq s \leqq t\right\}
$$

for integers $p \geqq 2$. We have

$$
G_{n+4} \subset G_{n+3} \subset A_{n+2} \cap C_{t}
$$

The integer $m$ is defined by the relation

$$
2^{4-2(m-1)}>t+1 \geqq 2^{4-2 m} \text {. }
$$

The requirement $(x, t) \in A_{n+1},(2.9)$, and $t+1<1$ yield

$$
3 \leqq m \leqq n+3, G_{p} \subset C_{\imath} \text { for } \quad p \geqq m .
$$

For $p \in\{2,3,4, \cdots\}$ the point $x_{p} \in R^{3}$ is defined as follows: If $x \neq 0$ then $x_{p}=x-3 \cdot 2^{-1-p}|x|^{-1} x$, and if $x=0$ we choose $x_{p}$ so that $\left|x_{p}\right|=3 \cdot 2^{-1-p}$ holds. We then set 


$$
H_{p}=\left\{(y, s):\left|y-x_{p}\right| \leqq 2^{-1-p}, t-2^{-2 p} \leqq s \leqq t\right\} .
$$

Then $H_{p} \subset G_{p}$ holds and (2.9), (2.10), and $|x|<1$ yield

$$
H_{p} \subset A_{p} \cap C_{t} \text { for } \quad p \geqq m \text {. }
$$

We set $C_{s}^{\prime}=R^{3} \times\{s\}$. For $s \in\left[t-2^{-2 p}, t\right]$ Lemma 1.2 yields

$$
\begin{aligned}
& \int_{G_{p} \cap C_{s}^{\prime}}|u|^{2} \\
& \leqq C 2^{-2 p}\left(\int_{G_{p} \cap C_{s}^{\prime}}|D u|^{2}\right)+C 2^{-3 p} \sup \left(|u|^{2}, H_{p} \cap C_{s}^{\prime}\right) .
\end{aligned}
$$

Integration of (2.12) with respect to $s$ and (2.11) yield

$$
\text { (2.13) } \int_{G_{p}}|u|^{2} \leqq C 2^{-2 p}\left(\int_{G_{p}}|D u|^{2}\right)+C 2^{-5 p} \sup \left(|u|^{2}, A_{p} \cap C_{t}\right) \text { if } p \geqq m \text {. }
$$

Observing $G_{m+1} \subset G_{m} \subset B_{1}, B_{1} \cup D=C_{0}, D \cap G_{m}=\varnothing$, we let $f_{1}, f_{2}, f_{3}$ be smooth functions from $C_{t}$ into [0,1] such that $f_{1}+f_{2}+f_{3}=1, f_{1}(y, s)=1$ for $(y, s) \notin B_{1}, f_{1}(y, s)=0$ for $(y, s) \notin D, f_{2}(y, s)=0$ for $(y, s) \notin B_{1}$, $f_{2}(y, s)=0$ for $(y, s) \in G_{m+1}, f_{2}(y, s)=1$ for $(y, s) \notin D \cup G_{m},\left|D f_{2}(y, s)\right| \leqq$ $C$ for $(y, s) \in D \cap B_{1},\left|D f_{2}(y, s)\right| \leqq C 2^{m}$ for $(y, s) \in G_{m}-G_{m+1}, f_{3}(y, s)=$ 0 for $(y, s) \notin G_{m}$ and $f_{3}(y, s)=1$ for $(y, s) \in G_{m+1}$ (note that $f_{j}$ is defined only on $C_{t}$ ): Using (1.5) and $x \in A_{n+1}$ we obtain

$$
\begin{array}{r}
\left|\int_{C_{t}} u_{,} u_{i} \phi_{, j}^{\prime} f_{1}\right|+\left|\int_{C_{t}} u_{j} u_{k} \psi_{, i j k}^{\prime} f_{1}\right| \\
\leqq C \int_{D \cap C_{t}}|u(y, s)|^{2}|y|^{-4} d y d s .
\end{array}
$$

We use integration by parts, (1.7), (1.5), the inequality $a b \leqq$ $\epsilon a^{2} / 2+\epsilon^{-1} b^{2} / 2,(2.13)$, and (2.9) to estimate

$$
\begin{aligned}
& \left|\int_{C_{1}} u_{j} u_{i} \phi_{, j}^{\prime} f_{2}\right|+\left|\int_{C_{t}} u_{j} u_{k} \psi_{,, i j k}^{\prime} f_{2}\right| \\
& \leqq\left|\int_{C_{t}} u_{j} u_{i, j} \phi^{\prime} f_{2}\right|+\left|\int_{C_{t}} u_{,} u_{i} \phi^{\prime} f_{2, j}\right| \\
& +\left|\int_{C_{\imath}} u_{j} u_{k, j} \psi_{,{ }_{, k}} f_{2}\right|+\left|\int_{C_{t}} u_{j} u_{k} \psi_{,{ }_{, k}} f_{2, j}\right| \\
& \leqq C\left(\int_{\left(B_{1} \cap C_{1}\right)-G_{m+1}}|u||D u|\left(\left|\phi^{\prime}\right|+\left|D^{2} \psi^{\prime}\right|\right)\right)
\end{aligned}
$$


(2.15)

$$
\begin{aligned}
& +C\left(\int_{D \cap B_{1} \cap C_{t}}|u|^{2}\left(\left|\phi^{\prime}\right|+\left|D^{2} \psi^{\prime}\right|\right)\right) \\
& +C \int_{G_{m}-G_{m+1}}|u|^{2}\left(\left|\phi^{\prime}\right|+\left|D^{2} \psi^{\prime}\right|\right) 2^{m}
\end{aligned}
$$

$$
\begin{aligned}
& \leqq C\left(\int_{B_{1} \cap C_{t}}|u||D u| 2^{3 m}\right)+C\left(\int_{B_{1} \cap C_{t}}|u|^{2}\right)+C \int_{G_{m}}|u|^{2} 2^{4 m} \\
& \leqq C 2^{3 m}\left(\int_{B_{1} \cap C_{t}}|u|^{2}\right)+C 2^{3 m}\left(\int_{B_{1} \cap C_{t}}|D u|^{2}\right) \\
& +C 2^{2 m}\left(\int_{G_{m}}|D u|^{2}\right)+C 2^{-m} \sup \left(|u|^{2}, A_{m} \cap C_{t}\right) \\
& \leqq C(t+1)^{-3 / 2}\left(\int_{B_{1} \cap C_{t}}|u|^{2}\right) \\
& +C(t+1)^{-3 / 2}\left(\int_{B_{1} \cap C_{t}}|D u|^{2}\right) \\
& +C 2^{2 m}\left(\int_{G_{m}}|D u|^{2}\right)+C 2^{-m} \sup \left(|u|^{2}, A_{m} \cap C_{t}\right) .
\end{aligned}
$$

We use (2.10), (1.5), (2.13), (2.8), and (2.10) to estimate

$$
\begin{aligned}
& \left|\int_{C_{t}} u_{l} u_{i} \phi_{, j}^{\prime} f_{3}\right|+\left|\int_{C_{t}} u_{j} u_{k} \psi_{, j, k}^{\prime} f_{3}\right| \\
& \quad \leqq C \int_{G_{m}}|u|^{2}\left(\left|D \phi^{\prime}\right|+\left|D^{3} \psi^{\prime}\right|\right) \\
& \leqq C\left(\sum_{p=m}^{n+3} \int_{G_{p}-G_{p+1}}|u|^{2}\left(\left|D \phi^{\prime}\right|+\left|D^{3} \psi^{\prime}\right|\right)\right) \\
& \quad+C \int_{G_{n+4}}|u|^{2}\left(\left|D \phi^{\prime}\right|+\left|D^{3} \psi^{\prime}\right|\right)
\end{aligned}
$$

(2.16) $\leqq C\left(\sum_{p=m}^{n+3} 2^{4 p} \int_{G_{p}}|u|^{2}\right)$

$$
\begin{aligned}
& +C\left(\int_{G_{n+4}}\left|D \phi^{\prime}\right|+\left|D^{3} \psi^{\prime}\right|\right) \sup \left(|u|^{2}, G_{n+4}\right) \\
\leqq & C\left(\sum_{p=m}^{n+3} 2^{2 p} \int_{G_{p}}|D u|^{2}\right)+C\left(\sum_{p=m}^{n+3} 2^{-p} \sup \left(|u|^{2}, A_{p} \cap C_{t}\right)\right) \\
& +C 2^{-n} \sup \left(|u|^{2}, A_{n+2} \cap C_{t}\right) \\
\leqq & C\left(\sum_{p=m}^{n+3} 2^{2 p} \int_{G_{p}}|D u|^{2}\right)+C\left(\sum_{p=1}^{n+3} 2^{-p} \sup \left(|u|^{2}, A_{p} \cap C_{t}\right)\right) .
\end{aligned}
$$


Combining (2.14), (2.15), (2.16), (2.10), $0<t+1<1$, and $f_{1}+f_{2}+f_{3}=1$ we obtain

$$
\begin{aligned}
& \left|\int_{C_{t}} u_{j} u_{i} \phi_{, j}^{\prime}\right|+\left|\int_{C_{t}} u_{j} u_{k} \psi_{,{ }_{l j k}}^{\prime}\right| \\
& \leqq \\
& \quad C(t+1)^{-3 / 2} \int_{C_{t}}|u(y, s)|^{2}(1+|y|)^{-4} d y d s \\
& \quad+C(t+1)^{-3 / 2}\left(\int_{B_{1} \cap C_{t}}|D u|^{2}\right) \\
& \quad+C\left(\sum_{p=m}^{n+3} 2^{2 p} \int_{G_{p}}|D u|^{2}\right) \\
& \quad+C\left(\sum_{p=1}^{n+3} 2^{-p} \sup \left(|u|^{2}, A_{p} \cap C_{t}\right)\right) .
\end{aligned}
$$

Since $(x, t) \notin A_{n}$, we know that either (I) $|x| \geqq 1-2^{-n}$ or (II) $t+1 \leqq 2^{-2 n}$ holds. If (I) is satisfied then $G_{p} \subset B_{p-4}$ for $m \leqq p \leqq n+3$ (see (2.4), (2.5), (2.7), (2.10), and use $\left.(x, t) \in A_{n+1}\right)$ and hence (see (2.5))

$$
\sum_{p=m}^{n+3} 2^{2 p} \int_{G_{p}}|D u|^{2} \leqq C \sum_{p=1}^{n+1} 2^{2 p} \int_{B_{p}}|D u|^{2}
$$

if (I) holds. If, on the other hand, (II) holds then (2.9) yields $m \geqq n+2$ and hence (2.9), (2.10), and (2.7) yield

$$
\sum_{p=m}^{n+3} 2^{2 p} \int_{G_{p}}|D u|^{2} \leqq C(t+1)^{-1} \int_{B_{1} \cap C_{\epsilon}}|D u|^{2}
$$

if (II) holds. Hence (2.18), (2.19), and $0<t+1<1$ yield

$$
\sum_{p=m}^{n+3} 2^{2 p} \int_{G_{p}}|D u|^{2} \leqq C\left(\sum_{p=1}^{n+1} 2^{2 p} \int_{B_{p}}|D u|^{2}\right)+C(t+1)^{-3 / 2} \int_{B_{1} \cap C_{1}}|D u|^{2} .
$$

Let $g_{1}, g_{2}$ be smooth functions from $R^{3}$ into [0,1] such that (see (2.4)) $g_{1}+g_{2}=1, g_{1}=1$ outside $F, g_{2}=1$ outside $E,\left|D g_{1}\right| \leqq C$, and $\left|D g_{2}\right| \leqq$ C. Using (1.1) (not (1.5)) we estimate

$$
\left|\int_{R^{3}} u_{\imath}(y,-1) \phi^{\prime}(y,-1) g_{1}(y) d y\right| \leqq C \int_{E}|u(y,-1)||y|^{-4} d y .
$$

We use the inequality

$$
\int_{R^{3}}|f|^{6} \leqq C\left(\int_{R^{3}}|D f|^{2}\right)^{3}
$$


valid for smooth functions $f: R^{3} \rightarrow R$ with compact support [3, p. 12], Hölder's inequality, and (1.1) to compute

$$
\begin{aligned}
& \left|\int_{R^{3}} u_{i}(y,-1) \phi^{\prime}(y,-1) g_{2}(y) d y\right| \\
& \leqq \int_{R^{3}}\left|g_{2}(y) u(y,-1)\right|\left|\phi^{\prime}(y,-1)\right| d y \\
& \leqq\left(\int_{R^{3}}\left|g_{2}(y) u(y,-1)\right|^{6} d y\right)^{1 / 6}\left(\int_{F}\left|\phi^{\prime}(y,-1)\right|^{6 / 5} d y\right)^{5 / 6} \\
& \leqq C\left(\int _ { R ^ { 3 } } \left(\left|D g_{2}(y)\right||u(y,-1)|\right.\right. \\
& \left.\left.+\left|g_{2}(y)\right||D u(y,-1)|\right)^{2} d y\right)^{1 / 2}(t+1)^{-1 / 4} \\
& \leqq C(t+1)^{-1 / 4}\left(\int_{F}|u(y,-1)|^{2} d y\right)^{1 / 2} \\
& +C(t+1)^{-1 / 4}\left(\int_{F}|D u(y,-1)|^{2} d y\right)^{1 / 2}
\end{aligned}
$$

Now we combine (2.17), (2.20), (2.21), (2.22), $g_{1}+g_{2}=1$, and (2.2) to write

$(2.23)$

$$
\begin{aligned}
& |u(x, t)| \\
& \leqq \\
& \quad C_{2}\left(\int_{E}|u(y,-1)||y|^{-4} d y\right) \\
& \quad+C_{2}(t+1)^{-1 / 4}\left(\int_{F}|u(y,-1)|^{2} d y\right)^{1 / 2} \\
& \quad+C_{2}(t+1)^{-1 / 4}\left(\int_{F}|D u(y,-1)|^{2} d y\right)^{1 / 2} \\
& \quad+C_{2}(t+1)^{-3 / 2}\left(\int_{C_{t}}|u(y, s)|^{2}(1+|y|)^{-4} d y d s\right) \\
& \quad+C_{2}(t+1)^{-3 / 2}\left(\int_{B_{1} \cap C_{t}}|D u|^{2}\right) \\
& \quad+C_{2}\left(\sum_{p=1}^{n+1} 2^{2 p} \int_{B_{p}}|D u|^{2}\right) \\
& \quad+C_{2}\left(\sum_{p=1}^{n+3} 2^{-p} \sup \left(|u|^{2}, A_{p} \cap C_{t}\right)\right),
\end{aligned}
$$

where $C_{2}$ is fixed (see $\S 1$ ). For $\epsilon>0$ we can use the inequality $a b \leqq \epsilon a^{2} / 2+\epsilon^{-1} b^{2} / 2$ to write 
$(2.24)$

$$
\begin{aligned}
\int_{E} \mid & \left.u(y,-1)|| y\right|^{-4} d y \\
& =\int_{E}\left(|u(y,-1)||y|^{-2}\right)\left(|y|^{-2}\right) d y \\
& \leqq\left(\epsilon^{-1} / 2\right)\left(\int_{E}|u(y,-1)|^{2}|y|^{-4} d y\right)+(\epsilon / 2)\left(\int_{E}|y|^{-4} d y\right)
\end{aligned}
$$

and, for $w=u$ or $w=D u$,

$$
(t+1)^{-1 / 4}\left(\int_{F}|w(y,-1)|^{2} d y\right)^{1 / 2}
$$

$$
\leqq\left(\epsilon^{-1} / 2\right)(t+1)^{-1 / 2}\left(\int_{F}|w(y,-1)|^{2} d y\right)+\epsilon / 2 .
$$

Since $\int_{E}|y|^{-4} d y$ is finite and $C_{2}$ is fixed, we can choose $\epsilon>0$ so that

$$
C_{2}\left((\epsilon / 2)\left(\int_{E}|y|^{-4} d y\right)+\epsilon\right) \leqq C_{2}^{-1} 2^{-12}
$$

holds. Now (2.23), (2.24), (2.25), (2.26), and $0<t+1<1$ yield (2.6).

LEMMA 2.2. There exists an absolute constant $\epsilon>0$ such that the following holds: If the conditions

$$
\begin{aligned}
& (t+1)^{-1} \int_{C_{t}}|u(y, s)|^{2}(1+|y|)^{-4} d y d s \leqq \epsilon, \\
& (t+1)^{-1} \int_{B_{1} \cap C_{t}}|D u|^{2} \leqq \epsilon, \\
& 2^{p} \int_{B_{p}}|D u|^{2} \leqq \epsilon
\end{aligned}
$$

are satisfied for all $t \in(-1,0)$ and $p \in\{1,2,3, \cdots\}$ then $u$ can be extended continuously to the closure of $A_{1}$ in $R^{3} \times R$.

Proof. We choose $\epsilon>0$ so that

$$
\text { (12) } C_{3} \epsilon \leqq C_{2}^{-1} 2^{-12}
$$

holds (see Lemma 2.1). Let $f: \bigcup_{n=1}^{\infty} A_{n} \rightarrow R^{+}$be a continuous function satisfying 


$$
C_{2}^{-1} 2^{n-10} \leqq f(x, t) \leqq C_{2}^{-1} 2^{n-7} \quad \text { if } \quad(x, t) \in A_{n+1}-A_{n},
$$

where $n \geqq 0$ (see (2.5)). We wish to show that (2.27) implies

$$
|u(x, t)| \leqq f(x, t) \text { for all }(x, t) \in \bigcup_{n=1}^{\infty} A_{n} .
$$

Assume, to the contrary, that (2.27) holds but (2.30) does not. Since $u$ is continuous on $R^{3} \times[-1,0)$ (see first paragraph of $\$ 2$ ) and the continuous function $f(x, t)$ tends to $\infty$ as $(x, t)$ tends to

$$
\{(x,-1):|x| \leqq 1\} \cup\{(x, t):|x|=1,-1 \leqq t<0\},
$$

there must exist $(x, t) \in \bigcup_{n=1}^{\infty} A_{n}$ such that (2.31) and (2.32) hold:

$$
|u(x, t)|=f(x, t)
$$

$$
|u(y, s)| \leqq f(y, s) \text { if } \quad(y, s) \in \bigcup_{n=1}^{\infty} A_{n} \quad \text { and } \quad s \leqq t
$$

Taking the limit as $t$ tends to -1 in (2.27) and using Fatou's lemma we obtain (recall (2.4))

$$
\int_{R^{3}}|u(y,-1)|^{2}(1+|y|)^{-4} d y \leqq \epsilon,
$$

$$
\int_{F}|D u(y,-1)|^{2} d y \leqq \epsilon .
$$

We define $n$ by the condition $(x, t) \in A_{n+1}-A_{n}$ and use Lemma 2.1, (2.33), (2.27), (2.32), the inequality $t+1 \geqq 2^{-2(n+1)}$ (which follows from $\left.(x, t) \in A_{n+1}\right),(2.29),(2.28)$, and $n \geqq 0$ to write

$$
\begin{aligned}
&|u(x, t)| \\
& \leqq 4 C_{3}(t+1)^{-1 / 2} \epsilon+C_{3}\left(\sum_{p=1}^{n+1} 2^{p} \epsilon\right) \\
&+C_{2}\left(\sum_{p=1}^{n+3} 2^{-p} \sup \left(f^{2}, A_{p} \cap C_{t}\right)\right)+C_{2}^{-1} 2^{-12} \\
& \leqq C_{3} 2^{n+3} \epsilon+C_{3} 2^{n+2} \epsilon+C_{2}\left(\sum_{p=1}^{n+3} 2^{-p}\left(C_{2}^{-1} 2^{p-8}\right)^{2}\right)+C_{2}^{-1} 2^{-12} \\
& \leqq C_{2}^{-1} 2^{n-12}+C_{2}^{-1} 2^{n-12}+C_{2}^{-1} 2^{-12} \\
& \leqq(3 / 4) C_{2}^{-1} 2^{n-10} \leqq(3 / 4) f(x, t) .
\end{aligned}
$$


However, (2.34) contradicts (2.31) since $|u(x, t)|=f(x, t) \quad$ is positive. Hence (2.27) implies (2.30).

We set $A=B(0,1 / 4) \times[-3 / 16,0)$ (see (1.14)). From (2.30) and (2.29) we conclude that $|u|$ is bounded on $A_{2}$. Hence the integrability of $D \phi$ and $D^{3} \psi$ on $A$ (see (1.5)), the boundedness of $D \phi, D^{3} \psi$ outside $A$, (1.6) and (1.1) allow us to extend the domain of definition of $u$ to include the closure of $A_{1}$ by substitution of $t=0$ in (2.2). The above integrability property allows us to construct infinite sequences of continuous functions ${ }^{m} f_{j}$ and ${ }^{m} g_{i j k}$ for $m=1,2,3, \cdots$ and $i, j, k \in\{1,2,3\}$ such that the restrictions of ${ }^{m} f_{j}$ and ${ }^{m} g_{i j k}$ to $A$ converge as $m \rightarrow \infty$ to $\phi_{, j}$ and $\psi_{, i j k}$, respectively, in the $L^{1}$ norm; and such that ${ }^{m} f_{j},{ }^{m} g_{i j k}$ coincide with $\phi_{, j}, \psi_{, i j k}$ outside $A$. We use (1.1), (1.5), (1.6) to define

$$
\begin{aligned}
{ }^{m} u_{i}(x, t)= & \int_{R^{3}} u_{i}(y,-1) \phi^{\prime}(y,-1) d y \\
& +\int_{R^{3} \times[-1, t]}\left(u_{j} u_{i}\left({ }^{m} f_{j}^{\prime}\right)-u_{j} u_{k}\left({ }^{m} g_{i j k}^{\prime}\right)\right)
\end{aligned}
$$

for $-1<t \leqq 0$, where $\phi^{\prime}$ is as in $(2.3),{ }^{m} f_{j}^{\prime}(y, s)={ }^{m} f_{j}(y-x, s-t)$, ${ }^{m} g_{i j k}^{\prime}(y, s)={ }^{m} g_{i j k}(y-x, s-t)$. The statements in this paragraph and (2.2) imply that ${ }^{m} u$ converges to $u$ uniformly on the closure of $A_{1}$. The conclusion of the lemma follows because each ${ }^{m} u$ is continuous.

3. The basic estimate and Hausdorfi measure. As before, $J_{q}$ is the interval in Theorem 1 , and its right endpoint is $t_{0}$. We recall (1.14) and we define $S(a, r)=\left\{x \in R^{3}:|x-a|=r\right\}$ for $a \in R^{3}$. The integral of $f$ over $S(a, r)$ with respect to area measure will be denoted $\int_{S(a, r)} f(x) d x$ for simplicity.

LEMMA 3.1. There exists an absolute constant $\delta>0$ such that the following holds: If $x_{0} \in R^{3}, 0<d<\left(\text { length }\left(J_{q}\right)\right)^{1 / 2}$, and condition

$$
\begin{gathered}
d^{-2} \int_{t_{0}-d^{2}}^{t_{0}} \int_{R^{3}}|v(x, t)|^{2}\left(1+\left|x-x_{0}\right| / d\right)^{-4} d x d t \\
\quad+\int_{t_{0}-d^{2}}^{t_{0}} \int_{B\left(x_{0}, 2 d\right)}|D v(x, t)|^{2} d x d t \leqq \delta d
\end{gathered}
$$

is satisfied then $v$ can be extended continuously to $\left(R^{3} \times J_{q}\right) \cup\left(V \times\left\{t_{0}\right\}\right)$, where $V$ is a neighborhood of $x_{0}$ in $R^{3}$. 
Proof. We fix $x_{0} \in R^{3}$ and $0<d<$ length $\left(J_{q}\right)^{1 / 2}$, and define functions $k_{1}, k_{2}: R \rightarrow\{t \in R: t \geqq 0\}$ by (see first paragraph of $\S 3$ )

$$
\begin{aligned}
k_{1}(t)= & d^{-2} \int_{R^{3}}|v(x, t)|^{2}\left(1+\left|x-x_{0}\right| / d\right)^{-4} d x \\
& +\int_{B\left(x_{0}, 2 d\right)}|D v(x, t)|^{2} d x \quad \text { if } \quad t \in\left(t_{0}-d^{2}, t_{0}\right),
\end{aligned}
$$

$$
\begin{aligned}
& k_{2}(r)=\int_{t_{0}-d^{2}}^{t_{0}} \int_{S\left(x_{0}, r\right)}|D v(x, t)|^{2} d x d t \quad \text { if } \quad r \in(0,2 d), \\
& k_{1}(t)=0=k_{2}(r) \text { if } t \notin\left(t_{0}-d^{2}, t_{0}\right) \text { and } \quad r \notin(0,2 d) .
\end{aligned}
$$

We let $M k_{\iota}$ be the cubic Hardy-Littlewood maximal function of $k_{i}[9, p$. 53]. That is,

$$
M k_{\iota}(a)=\sup \left\{(2 b)^{-1} \int_{a-b}^{a+b} k_{\iota}(c) d c: 0<b<\infty\right\} .
$$

We let \|\|$_{1}$ denote the $L^{1}$ norm and | | denote Lebesgue measure. The Hardy-Littlewood theorem for $L^{1}[9,(3.5)$ on p. 55] implies that (3.4) holds for some absolute constant $C_{4}$ :

$$
|A| \leqq d^{2} / 8 \quad \text { where } \quad A=\left\{t: M k_{1}(t)>C_{4}\left(d^{2} / 8\right)^{-1}\left\|k_{1}\right\|_{1}\right\}
$$

$$
|B| \leqq d / 8 \quad \text { where } \quad B=\left\{r: M k_{2}(r)>C_{4}(d / 8)^{-1}\left\|k_{2}\right\|_{1}\right\} .
$$

We have $\left|\left\{e \in[d / 2, d]: t_{0}-e^{2} \in A\right\}\right| \leqq d^{-1}|A| \leqq d / 8$. This and (3.4) imply the existence of $d_{0} \in[d / 2, d]$ such that $t_{0}-d_{0}^{2} \notin A$ and $d_{0} \notin B$. Now (3.2), (3.3), and (3.4) yield

$$
\begin{aligned}
& (2 b)^{-1} \int_{t_{0}-d_{0}^{2}}^{t_{0}-d_{0}^{2}+b} d^{-2} \int_{R^{3}}|v(x, t)|^{2}\left(1+\left|x-x_{0}\right| / d\right)^{-4} d x d t \\
& \quad+(2 b)^{-1} \int_{t_{0}-d_{0}^{2}}^{t_{0}-d_{0}^{2}+b} \int_{B\left(x_{0}, 2 d\right)}|D v(x, t)|^{2} d x d t \\
& \leqq 8 C_{4} d^{-2}\left\|k_{1}\right\|_{1} \text { for } 0<b<d_{0}^{2}, \\
& (2 b)^{-1} \int_{t_{0}-d^{2}}^{t_{0}} \int_{d_{0}-b \leqq\left|x-x_{0}\right| \leqq d_{0}+b}|D v(x, t)|^{2} d x d t \\
& \leqq 8 C_{4} d^{-1}\left\|k_{2}\right\|_{1} \text { for } 0<b \leqq d_{0} .
\end{aligned}
$$

Defining $u$ by means of (2.1), using $d / 2 \leqq d_{0} \leqq d$, rewriting (3.5) and (3.6) in terms of $u$, and recalling (2.4), we obtain (3.7) and (3.8): 


$$
\begin{gathered}
(t+1)^{-1} \int_{C_{t}}|u(y, s)|^{2}(1+|y|)^{-4} d y d s \\
+(t+1)^{-1} \int_{B_{1} \cap C_{t}}|D u(y, s)|^{2} d y d s \\
\leqq C d^{-1}\left\|k_{1}\right\|_{1} \text { for }-1<t<0, \\
2^{p} \int_{B_{p}}|D u|^{2} \leqq C d^{-1}\left\|k_{2}\right\|_{1} \text { for } p=1,2,3, \cdots .
\end{gathered}
$$

From (3.2) we obtain

$$
\begin{aligned}
\left\|k_{2}\right\|_{1} & \leqq\left\|k_{1}\right\|_{1} \\
= & d^{-2} \int_{t_{0}-d^{2}}^{t_{0}} \int_{R^{3}}|v(x, t)|^{2}\left(1+\left|x-x_{0}\right| / d\right)^{-4} d x d t \\
& +\int_{t_{0}-d^{2}}^{t_{0}} \int_{B\left(x_{0}, 2 d\right)}|D v(x, t)|^{2} d x d t .
\end{aligned}
$$

Now (3.7), (3.8), and (3.9) imply the existence of an absolute constant $\delta>0$ such that (3.1) yields (2.27). The conclusion of the lemma follows from Lemma 2.2 .

We fix the constant $\delta$ in Lemma 3.1 and set

$$
\left.Q=\left\{\left(x_{0}, 2 d\right) \in R^{3} \times\left(0,2 \text { (length }\left(J_{q}\right)\right)^{1 / 2}\right):(3.1) \text { does not hold }\right\}
$$

LEMMA 3.2. There exists a finite constant $N$ that depends only on $C_{1}$ (see (1.6)) such that the following holds: If

$$
0<d<\left(\text { length }\left(J_{q}\right)\right)^{1 / 2}, B \subset R^{3},(b, 2 d) \in Q \quad \text { if } \quad b \in B,
$$
$\{B(b, 2 d): b \in B\}$ is a family of disjointed sets

is satisfied then the number of points in $B$ is at most $N / d$.

Proof. Let (3.11) hold. The disjointedness hypothesis implies that (3.12) holds for some absolute constant $C_{5}$ :

$$
\sum_{b \in B}(1+|x-b| / d)^{-4} \leqq C_{5} \quad \text { for every } \quad x \in R^{3}
$$

Now (3.11), (3.10), (3.12), and (1.6) yield 


$$
\begin{aligned}
= & \sum_{b \in B} \delta d \\
\leqq & \sum_{b \in B} d^{-2} \int_{t_{0}-d^{2}}^{t_{0}} \int_{R^{3}}|v(x, t)|^{2}(1+|x-b| / d)^{-4} d x d t \\
& +\sum_{b \in B} \int_{t_{0}-d^{2}}^{t_{0}} \int_{B(b, 2 d)}|D v(x, t)|^{2} d x d t \\
\leqq & C_{5} d^{-2} \int_{t^{0}-d^{2}}^{t_{0}} \int_{R^{3}}|v(x, t)|^{2} d x d t \\
& +\int_{t_{0}-d^{2}}^{t_{0}} \int_{R^{3}}|D v(x, t)|^{2} d x d t \leqq C_{5} C_{1}+C_{1} .
\end{aligned}
$$

Hence we can set $N=\left(C_{5} C_{1}+C_{1}\right) / \delta$.

The following lemma is a consequence of the Besicovich covering theorem $[2,2.8 .14,2.8 .9]$.

LEMMA 3.3. There exists an integral absolute constant $K$ with the following property: If $0<d<\infty$ and $A \subset R^{3}$ then there exist $Y_{k} \subset A$ for $k=1,2, \cdots, K$ such that (I) and (II) hold:

(I) $\quad A \subset \cup\left\{B(y, 2 d): y \in \bigcup_{k=1}^{K} Y_{k}\right\}$

(II) For each $k,\left\{B(y, 2 d): y \in Y_{k}\right\}$ is a family of disjointed sets.

We can now finish the proof of Theorem 1. Let $A$ be the set of points $x_{0} \in R^{3}$ such that (3.1) fails to hold for every $d$ satisfying $0<d<\left(\text { length }\left(J_{q}\right)\right)^{1 / 2}$. Lemma 3.1 implies that there exists an open set $U \subset R^{3}$ such that $A \cup U=R^{3}$ and $v$ can be extended to a continuous function on

$$
\left(R^{3} \times J_{q}\right) \cup\left(U \times\left\{t_{0}\right\}\right) .
$$

We set $S=R^{3}-U$. Since $S \subset A$, all tht remains to show is that the 1 dimensional Hausdorff measure of $A$ is at most $4 K N$.

It suffices to show $\left[2\right.$, p. 171] that for every $0<d<\left(\text { length }\left(J_{q}\right)\right)^{1 / 2}$ there exists $Y \subset R^{3}$ such that

and

$$
A \subset \cup\{B(y, 2 d): y \in Y\}
$$

$$
\sum_{y \in Y} \operatorname{diameter}(B(y, 2 d)) \leqq 4 K N
$$

We apply Lemma 3.3 to find sets $Y_{k} \subset A$ satisfying (I) and (II). Lemma 
3.2, (3.10), and the definition of $A$ yield $\Sigma_{y \in Y_{k}}(4 d) \leqq 4 N$ for each $k$. Hence, setting $Y=\bigcup_{k=1}^{K} Y_{k}$, we obtain $\sum_{y \in Y}(4 d) \leqq 4 K N$. Theorem 1 is proved.

\section{REFERENCES}

1. F. J. Almgren, Jr., Existence and regularity almost everywhere of solutions to elliptic variational problems with constraints, Memoirs of the American Mathematical Society 165, Providence, R. I., 1976.

2. H. Federer, Geometric Measure Theory, Springer-Verlag, New York, 1969.

3. O. A. Ladyzhenskaya, The Mathematical Theory of Viscous Incompressible Flow, revised English edition, Gordon \& Breach, New York, 1964.

4. J. Leray, Sur le mouvement d'un liquide visqueux emplissant l'espace, Acta Math., 63 (1934), 193-248.

5. B. Mandelbrot, Les Objets Fractals, Flammarion, Paris, 1975.

6. V. Scheffer, Géométrie fractale de la turbulence. Équations de Navier-Stokes et dimension de Hausdorff, C. R. Acad. Sci. Paris, 282 (January 12, 1976), Série A 121-122.

7. - Turbulence and Hausdorff dimension, to appear in the proceedings of the conference on turbulence held at U. of Paris at Orsay in June, 1975; Lecture Notes in Mathematics, Springer-Verlag, New York.

8. M. Shinbrot, Lectures on Fluid Mechanics, Gordon \& Breach, New York, 1973.

9. E. M. Stein and G. Weiss, Introduction to Fourier Analysis on Euclidean Spaces, Princeton Univ. Press, Princeton, 1971.

Received April 6, 1976.

STANFORD UNIVERSITY

STANFORD, CA 94305 


\section{PACIFIC JOURNAL OF MATHEMATICS}

\section{EDITORS}

RICHARI) ARENS (Managing Editor)

University of California

Los Angeles, CA 90024

R. A. Beaumiont

University of Washington

Seattle, WA 98105

\section{J. DugunduI}

Department of Mathematics University of Southern California Los Angeles, CA 90007

D. Gilbarg and J. Milgram Stanford University

Stanford, CA 94305

\section{ASSOCIATE EDITORS}

E. F. BECKENBACH
B. H. NEUMANN

F. Wolf

K. YoshidA

\section{SUPPORTING INSTITUTIONS}

UNIVERSITY OF BRITISH COLUMBIA CALIFORNIA INSTITUTE OF TECHNOLOGY

UNIVERSITY OF CALIFORNIA

MONTANA STATE UNIVERSITY

UNIVERSITY OF NEVADA

NEW MEXICO STATE UNIVERSITY

OREGON STATE UNIVERSITY

UNIVERSITY OF OREGON

OSAKA UNIVERSITY

\author{
UNIVERSITY OF SOUTHERN CALIFORNIA \\ STANFORD UNIVERSITY \\ UNIVERSITY OF HAWAII \\ UNIVERSITY OF TOKYO \\ UNIVERSITY OF UTAH \\ WASHINGTON STATE UNIVERSITY \\ UNIVERSITY OF WASHINGTON \\ AMERICAN MATHEMATICAL SOCIETY
}

The Supporting Institutions listed above contribute to the cost of publication of this Journal, but they are not owners or publishers and have no responsibility for its contents or policies.

Mathematical papers intended for publication in the Pacific Journal of Mathematics should be in typed form or offset-reproduced (not dittoed), double spaced with large margins. Underline Greek letters in red, German in green, and script in blue. The first $p: 1<$ graph or two must be capable of being used separately as a synopsis of the entire paper. Items of the biblography should not be cited there unless absolutely necessary, in which case they must he identified by author and Journal, rather than by item number. Manuscripts, in duplicate, may be sent to any one of the four editors. Please classify according to the scheme of Math. Reviews, Index to Vol. 39. All other communications should be addressed to the managing editor, or Elaine Barth, University of California, Los Angeles, California, 90024.

100 reprints are provided free for each article, only if page charges have been substantially paid. Additional copies may be obtained at cost in multiples of 50 .

The Pacific Journal of Mathematics is issued monthly as of January 1966. Regular subscription rate: $\$ 72.00$ a year (6 Vols., 12 issues). Special rate: $\$ 36.00$ a year to individual members of supporting institutions.

Subscriptions, orders for back numbers, and changes of address should be sent to Pacific Journal of Mathematics, 103 Highland Boulevard, Berkeley, California, 94708.

PUBLISHED BY PACIFIC JOURNAL OF MATHEMATICS, A NON-PROFIT CORPORATION Printed at Jerusalem Academic Press, POB 2390, Jerusalem, Israel.

\section{Copyright (C) 1976 Pacific Journal of Mathematics} All Rights Reserved 


\section{Pacific Journal of Mathematics}

\section{Vol. 66, No. 2 December, 1976}

Gerald A. Beer, Tax structures whose progressivity is inflation neutral..... 305

William M. Cornette, A generalization of the unit interval............. 313

David E. Evans, Unbounded completely positive linear maps on

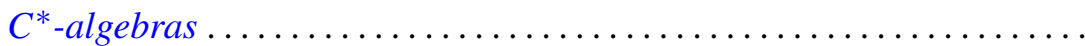

Hector O. Fattorini, Some remarks on convolution equations for

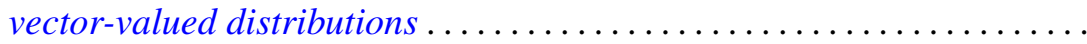

Amassa Courtney Fauntleroy, Automorphism groups of unipotent groups of

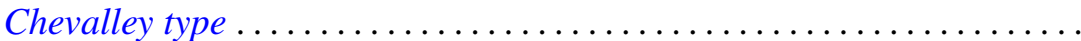

Christian C. Fenske and Heinz-Otto Peitgen, On fixed points of zero index in

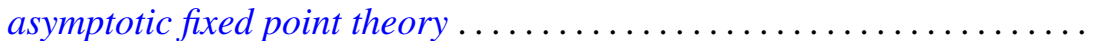

Atsushi Inoue, On a class of unbounded operator algebras. II ............

Herbert Meyer Kamowitz, The spectra of endomorphisms of algebras of

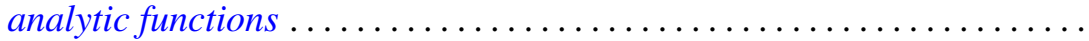

Jimmie Don Lawson, Embeddings of compact convex sets and locally compact cones ....................................

William Lindgren and Peter Joseph Nyikos, Spaces with bases satisfying certain order and intersection properties .....................

Emily Mann Peck, Lattice projections on continuous function spaces ...... 477

Morris Marden and Peter A. McCoy, Level sets of polynomials in $n$ real variables...

Francis Joseph Narcowich, An imbedding theorem for indeterminate Hermitian moment sequences......................

John Dacey O'Neill, Rings whose additive subgroups are subrings ...

Chull Park and David Lee Skoug, Wiener integrals over the sets bounded by sectionally continuous barriers .....................

Vladimir Scheffer, Partial regularity of solutions to the Navier-Stokes equations.

Eugene Spiegel and Allan Trojan, On semi-simple group algebras. II

Katsuo Takano, On Cameron and Storvick's operator valued function space integral 